\title{
Cannabis use and cognition in schizophrenia
}

\author{
Else-Marie Løberg ${ }^{1,2 *}$ and Kenneth Hugdahl ${ }^{1,2}$ \\ Department of Biological and Medical Psychology, University of Bergen, Bergen, Norway \\ 2 Division of Psychiatry, Haukeland University Hospital, Bergen, Norway
}

\section{Edited by:}

Vince D. Calhoun, University of

New Mexico, USA

\section{Reviewed by:}

Francesca Filbey, The Mind Research Network, USA

Vince D. Calhoun, University of

New Mexico, USA

*Correspondence:

Else-Marie Løberg, Division of

Psychiatry, Helse-Bergen HF,

Haukeland University Hospital,

Forskningsenheten, Bergen Mental

Health Research Center, 5045 Bergen,

Norway.

e-mail: else.marie.loeberg@psych.uib.no
People with schizophrenia frequently report cannabis use, and cannabis may be a risk factor for schizophrenia, mediated through effects on brain function and biochemistry. Thus, it is conceivable that cannabis may also influence cognitive functioning in this patient group. We report data from our own laboratory on the use of cannabis by schizophrenia patients, and review the existing literature on the effects of cannabis on cognition in schizophrenia and related psychosis. Of the 23 studies that were found, 14 reported that the cannabis users had better cognitive performance than the schizophrenia non-users. Eight studies reported no or minimal differences in cognitive performance in the two groups, but only one study reported better cognitive performance in the schizophrenia non-user group. Our own results confirm the overall impression from the literature review of better cognitive performance in the cannabis user group. These paradoxical findings may have several explanations, which are discussed. We suggest that cannabis causes a transient cognitive breakdown enabling the development of psychosis, imitating the typical cognitive vulnerability seen in schizophrenia. This is further supported by an earlier age of onset and fewer neurological soft signs in the cannabis-related schizophrenia group, suggesting an alternative pathway to psychosis.

Keywords: schizophrenia, psychosis, cannabis, neurocognition, substance abuse, neuropsychological functioning illegal drugs

\section{INTRODUCTION}

A history of cannabis use is more common in schizophrenia than in the normal population (Regier et al., 1990; Arseneault et al., 2004b; Barnes et al., 2006). Life-time cannabis use has been reported to be as high as $64.4 \%$ in patients with schizophrenia (Barnes et al., 2006), and Løberg et al. (2003) found that $45 \%$ of schizophrenia patients participating in research studies had a history of previous cannabis use. Since cannabis may be a risk factor for schizophrenia, mediated through changes in brain functioning and biochemistry, cannabis may also have an effect on cognitive functioning in this patients group. In a preliminary study in our laboratory we were struck by apparent paradoxical positive effects of cannabis on cognition in patients with schizophrenia (Løberg et al., 2003, 2008). These preliminary findings prompted a review of the existing literature on the relationship between cannabis use and cognitive functioning in schizophrenia. For this purpose, we found 23 studies (see Table 1) that have looked at the relationship between cannabis use and cognitive impairments in schizophrenia. The results from the review are discussed and possible explanations suggested.

\section{CANNABIS USE - A RISK FACTOR FOR SCHIZOPHRENIA?}

Longitudinal studies have reported an increased risk for schizophrenia and other psychoses after cannabis use. In two largescale Swedish studies, the same cohort of about 50000 military conscripts were for followed longitudinally over 15 and 26 years. Dose-dependent relationships were found between cannabis use at 18 years of age and a later diagnosis of schizophrenia (Andreasson et al., 1987; Zammit et al., 2002). Cannabis have also been shown to increase the rate of conversion to psychosis in individuals at risk for psychosis (Kristensen and Cadenhead, 2007). Furthermore, several large-scale longitudinal studies have reported a relationship between cannabis use in adolescence and later symptoms of psychosis in the normal population (Tien and Anthony, 1990; Arseneault et al., 2002; van Os et al., 2002; Fergusson et al., 2003; Stefanis et al., 2004; Ferdinand et al., 2005; Henquet et al., 2005a). In one study, cannabis use at age 18 and 21 led to 3.7 and 2.3 higher rates of psychotic symptoms, respectively (Fergusson et al., 2003). The relationship between cannabis and schizophrenia seems fairly specific to schizophrenia, as compared to other mental disorders (Chambers et al., 2001; Degenhardt et al., 2007; Di Forti et al., 2007; Moore et al., 2007), and cannot be explained by potentially confounding factors, like premorbid disorders, drug use, intoxication, personality traits, sosiodemographic markers and intellectual ability (Smit et al., 2004; Moore et al., 2007). Accordingly, five recent reviews concluded with an increased risk for schizophrenia and psychosis in individuals who have used cannabis (Arseneault et al., 2004b; Macleod et al., 2004; Smit et al., 2004; Henquet et al., 2005b; Semple et al., 2005; Moore et al., 2007).

An alternative explanation is what can be called reversed causality, namely that schizophrenia patients use cannabis as a form of self-medication, although existing data does not seem to support this hypothesis (Chambers et al., 2001). An important argument against reversed causality is an "order-effect"; i.e. cannabis use seems to occur before the outbreak of psychosis, and not the other way around (Linszen et al., 1994; Degenhardt et al., 2007; Corcoran et al., 2008). Furthermore, in contrast to a self-medication hypothesis, the psychoactive substance in cannabis, delta-(9)-tetrahydrocannabinol (THC), increases, and not decreases, anxiety (Fusar-Poli et al., 2009; Morrison et al., 2009). Several studies have also shown that THC increases symptoms 
Table 1 | Overview of 23 studies on the effects of cannabis/drug use in schizophrenia and related psychoses on cognition by $n$, drug type, diagnoses, type of drug use, and results.

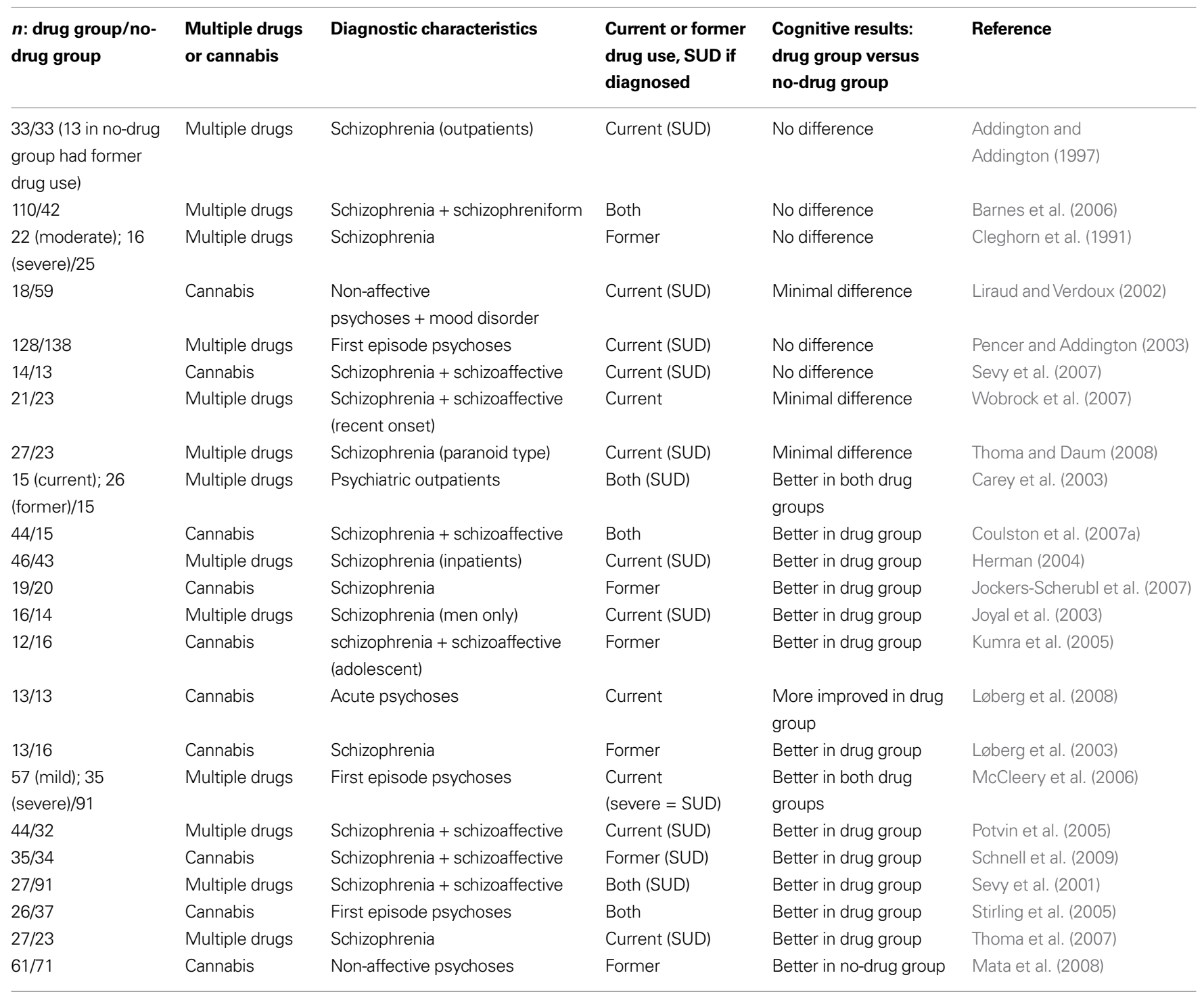

of psychosis and cognitive impairments (D'Souza et al., 2005; Morrison et al., 2009), with a possible increased sensitivity in schizophrenia to the adverse effects of THC (D'Souza et al., 2004). Moreover, cannabis has been shown to have clinical significance. Cannabis use in schizophrenia can lead to worsened illness prognoses; worsened clinical outcome, longer psychotic episodes, more relapse and re-hospitalizations, poorer social functioning, more frequent relapses, poorer compliance, and increased treatment needs (Linszen et al., 1994; Caspari, 1999; Grech et al., 2005). Thus, taken together, the available data seem to point to cannabis use as increasing psychotic symptoms, and increasing the vulnerability for a psychotic outbreak. For example, Moore and colleagues have argued that we now know enough to warn young people about the risk for psychosis after cannabis use (Moore et al., 2007).

However, most individuals do not develop schizophrenia after cannabis use, suggesting that a heightened risk for a development of psychosis must be related to other vulnerability factors. Verdoux
(2004) found that subjects with established vulnerability for psychoses showed a stronger risk of follow-up psychosis after cannabis use than individuals without such vulnerability. The relationship between cannabis use and psychosis may also be genetically mediated. In a longitudinal study of 803 individuals, an interaction between the Val allele of the Catechol-O-methyltransferase (COMT) gene and adolescent cannabis use significantly increased the likelihood of exhibiting psychotic symptoms and the development of schizophreniform disorders (Caspi et al., 2005). In accordance with this, an interaction between the COMTVal allele and sensitivity for psychosis and cognitive effects of the psychoactive substance in cannabis has been found in individuals with psychosis and their relatives (Henquet et al., 2006, 2009).

\section{CANNABIS AND BRAIN FUNCTION}

The relationship between cannabis and schizophrenia may be attributed to effects of cannabis on brain functioning and biochemistry. The endogenous cannabinoid system may directly or 
indirectly be involved in the development of the effects of cannabis on symptoms of psychosis and cognition (Solowij and Michie, 2007). THC affects cannabinoid receptors, which are distributed with high density in the cerebral cortex, including brain regions implicated in schizophrenia (D'Souza et al., 2005). The endogenous cannabinoid system interacts with the dopaminergic system of the brain, and THC influence dopamine synthesis and uptake (D'Souza et al., 2005). Abnormalities of the endogenous cannabinoid system in schizophrenia, not caused by cannabis use, have also been reported. Increased levels of endogenous cannabinoids have been found in the frontal cortex (Dean et al., 2001), in addition to elevated levels of endogenous cannabinoids in the cerebral spinal fluids (Leweke et al., 1999).

A stronger relationship between adolescent cannabis use and psychosis or schizophrenia, as compared to adult use, has been reported in several studies (Caspi et al., 2005; Konings et al., 2008). Even though some of these findings can be explained by an increased cumulative exposure to cannabis with earlier onset of cannabis use, it may also suggest that a developing brain is more vulnerable to the effects of cannabis than a matured brain.

However although there seems to be ample evidence for the influence of cannabis on the development and outbreak of psychosis or schizophrenia (Moore et al., 2007), possibly mediated by adverse effects on brain functioning acting on the dopaminergic system (D'Souza et al., 2005), much less is known regarding the effects of cannabis use on cognitive functioning in schizophrenia. If cannabis influences schizophrenia neurodevelopment and brain functioning, it could be expected that cannabis use may impact on cognitive functioning in this patients group. The aim of the present review was therefore to examine the relationship between cannabis use and cognitive functioning in schizophrenia.

\section{COGNITION IN PATIENTS WHO USE CANNABIS - A PARADOX}

Cognitive impairment is now universally recognized as a core feature of schizophrenia, and clinically relevant cognitive impairments are observed in a majority of patients with schizophrenia (Green, 1996; Palmer et al., 1997, 2009). Cognitive impairment is often observed before the development of psychosis and in close relatives, and cognitive symptoms may also reside after clinical symptoms have been reduced or are no longer seen (Neuchterlein et al., 1994; Weinberger, 1995; Heaton et al., 2001; Gschwandtner et al., 2003), Thus, it is clear that eventual effects of cannabis use on cognitive functioning in schizophrenia would be of both theoretical value for the understanding of the disorder, and of clinical relevance for the diagnosis and treatment of the disorder. Intuitively, a worsened outcome on cognitive functioning would be expected after cannabis use, since cannabis has negative effects on psychosis in general, and from findings that cannabis use impairs illness prognosis (Linszen et al., 1994; Caspari, 1999; Grech et al., 2005), in addition to the adverse effects of cannabis on brain functioning (D'Souza et al., 2004).

For this purpose we reanalyzed previously collected data in our laboratory on cognitive performance in schizophrenia patients, including cannabis use as an explanatory variable (data from Løberg et al., 2003, 2008). Information on the history of cannabis use was based on the patients' clinical records and therapist questionnaires, and was further validated through SCID-interviews. Surprisingly, we found that patients with schizophrenia who had a history of

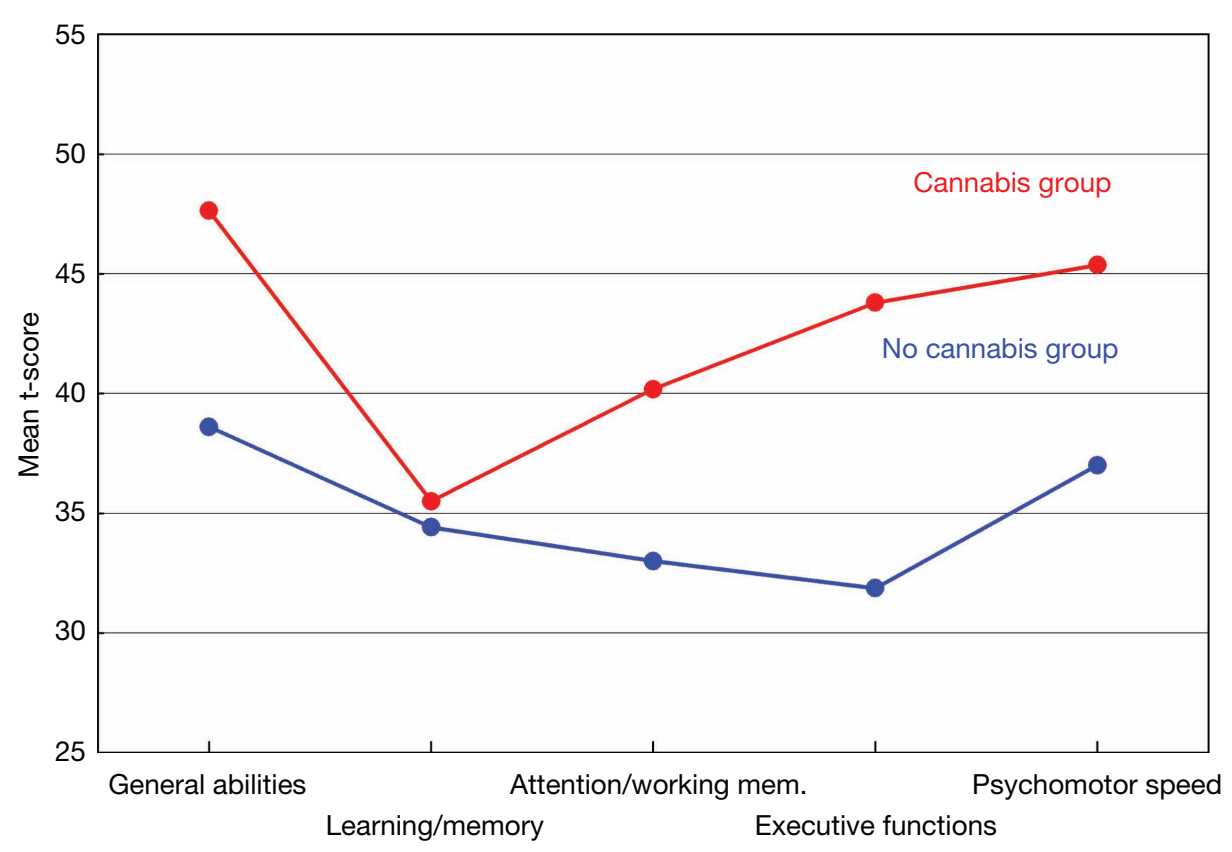

FIGURE 1 | Mean T-scores for the cannabis and no-cannabis group for the five cognitive functions. General abilities = general verbal and visuospatial abilities = WAIS (Information, Vocabulary, Block Design), Verbal Fluency (FAS), Rey-Osterrieth Complex Figure test, Wisconsin Card Sorting Test (WCST). Learning/memory = California Verbal Learning Test (CVLT) II, Rey-Osterrieth
Complex Figure Test. Attention/working mem. = attention/working memory = Digit Vigilance Test, Calcap Continuous Performance Test (CPT), Trail Making Test B. Execute functions = Wisconsin Card Sorting Test (WCST), Stroop Test. Psychomotor speed $=$ Trail Making Test A, Grooved Pegboard Test, Fingertapping Test. 
cannabis use scored significantly above their fellow counterparts without a history of cannabis use (see Figure 1). This was found for almost all cognitive functions investigated, such as general intellectual ability, executive functions, attention, working memory and psychomotor speed. These results did not change when other illegal drugs where controlled for, and there were no differences in the two groups with regard to clinical variables (Løberg et al., 2003).

In a second, prospective, study of patients with acute psychosis we assessed cognitive function at admission to a psychiatric emergency ward, after 6 weeks, and after 3 months. Information on the history of cannabis use was based on patient's clinical records and the Clinician Drug Use Scale (Drake et al., 1990), and was further validated through urine samples. The patients with both cannabis use and psychosis showed a significantly larger improvement in their cognitive performance in the three months after admission, as compared to the psychotic patients with no cannabis use. Both groups showed cognitive impairments at admission, but these were more prevalent in the non-cannabis psychosis group (see Figure 2; Løberg et al., 2008).

\section{COGNITION IN PATIENTS WHO USE CANNABIS - A LITERATURE REVIEW}

The paradoxical results reported by Løberg et al. (2003, 2008) seem to be consistent with several other studies on the relationship between cognition, cannabis and/or illegal drugs and schizophrenia (Joyal et al., 2003; Jockers-Scherubl et al., 2007). We performed a PubMed search on all combinations of the following search words: cannabis, substance, schizophr ${ }^{\star}$, psychos ${ }^{\star}$, $\operatorname{cognit}^{*}$ and neuropsych ${ }^{*}$, and searched the reference lists for all included papers of other studies covering this topic. This resulted in 23 studies comparing schizophrenia and related psychoses with and without cannabis use (alone or in combination with other substances) on cognitive performance (see Table 1 for further details).

Fourteen of the studies listed in Table 1 reported that the cannabis groups showed better cognitive performance than the no-cannabis groups (Sevy et al., 2001; Carey et al., 2003; Joyal et al., 2003; Løberg et al., 2003, 2008; Herman, 2004; Kumra et al., 2005; Potvin et al., 2005; Stirling et al., 2005; McCleery et al., 2006; Coulston et al., 2007a; Jockers-Scherubl et al., 2007; Thoma et al., 2007; Schnell et al., 2009). Eight of the studies in Table 1 reported no or minimal differences in cognitive performance in the two groups (Cleghorn et al., 1991; Addington and Addington, 1997; Liraud and Verdoux, 2002; Pencer and Addington, 2003; Barnes et al., 2006; Sevy et al., 2007; Wobrock et al., 2007; Thoma and Daum, 2008), and one study reported better cognitive performance in the no-cannabis compared to the drug group (Mata et al., 2008).

Most of the studies in Table 1 have small " $n$ ", and may therefore be influenced by Type-II statistical errors (false negatives), underestimating group differences due to lack of power. For instance, Thoma and Daum (2008) suggested that this may have been a problem in their 2008 study, influencing their conclusion of no differences between the groups. Furthermore, some of the studies included diverse drug use in addition to cannabis use, for instance alcohol and opiates in clusters of stimulating and/or hallucinatory illegal drugs. These drugs may have different, and sometimes opposite effects on brain functioning and neurochemistry, and consequently on cognition. In the overview in Table 1, all studies included cannabis; as a high frequent drug together with other drugs used, or as the only drug used. Thus, no study was included that did not include cannabis. Previous drug

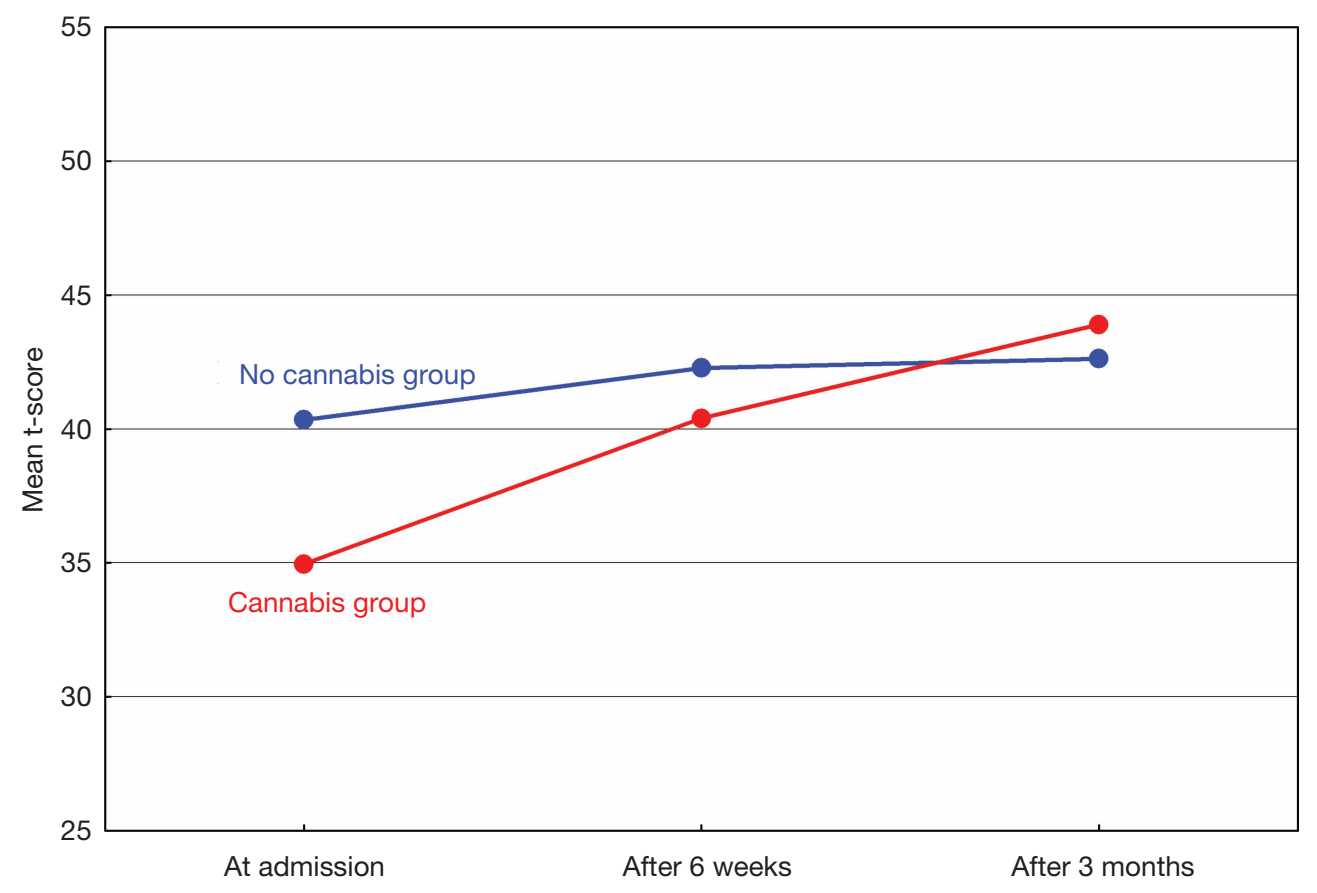

FIGURE 2 | Mean neuropsychological T-scores for the cannabis and no-cannabis group at admission, after 6 weeks and 3 months. 
use versus current drug use is included in Table $\mathbf{1}$ as a separate factor since this may have influenced the results. Current drug use may influence cognition by means of persisting intoxication effects or more acute effects on brain functioning, thus creating a "false" cognitive impairment not otherwise present. Furthermore, the use of diagnostic criteria is noted, yielding a SUD, since this usually means that the patients meet criteria for abuse or addictive behavior, and that the drug use has negative consequences for everyday living. This may bias the drug groups to consist of quite heavy users due to the exclusion of patients without a SUD diagnosis who nevertheless may have a frequent drug problem. An example of this is the study by Addington and Addington (1997) where it was reported that the no-drug group actually included 13 patients with previous drug use. Another problem when comparing the studies in Table 1 is the different diagnostic groups included in the studies, possibly with different levels of cognitive vulnerability.

Coulston et al. (2007b) did not find consistent neuropsychological patterns of cannabis use on cognition when examining seven studies (one of these studies reported intoxications effects, though), and attributed this to methodological variability between and methodological limitations within the studies. Methodological and clinical heterogeneity is also a problem in studies comparing differences in brain structure and function between drug and nodrug groups by means of brain-imaging methods, and inconsistent results have been reported (Quickfall and Crockford, 2006; Rais et al., 2008; Wobrock et al., 2009).

\section{CONCLUSION LITERATURE REVIEW}

Table 1 show that a majority of the studies report better cognitive functioning in the cannabis-related schizophrenia and psychosis groups compared to non-drug groups. This conclusion is supported even when confounding factors, like age, years of education, premorbid IQ, medical history, substance use, and psychiatric symptoms (Coulston et al., 2007a) are controlled for. Likewise, Potvin et al. (2008) argued that most studies have shown superior neuropsychological functioning in cannabis use and schizophrenia combined, then in schizophrenia patients alone (Potvin et al., 2008).

\section{EXPLANATIONS FOR THE PARADOXICAL EFFECT}

The seemingly paradoxical cognitive findings in cannabis-related schizophrenia could have several explanations. One explanation is that the group differences in cognition are attributed to superior social skills in the cannabis schizophrenia groups, making them "skillful" enough to get hold of illegal drugs. Superior social skills are however not consistent with the finding of poorer prognosis in this group. Few studies have, however, examined this directly, and the issue therefore remains unresolved. Two Norwegian studies reported poorer premorbid functioning in psychosis patients who also abused illegal drugs (Ringen et al., 2008), and better premorbid social functioning and poorer premorbid academic functioning in this group (Larsen et al., 2006), respectively. It has also been suggested that the group differences could be caused by cannabis having a protective or positive influence on brain functioning (Coulston et al., 2007a). Based on the effects of cannabis on brain function and prognosis of the psychosis, this is not supported by the existing data.
A second explanation could be that cannabis imitates the typical cognitive vulnerability seen in schizophrenia. The major psychoactive component in cannabis, THC, creates transient negative effects on cognitive functioning and psychotic symptoms (D'Souza et al., 2005; Semple et al., 2005; Morrison et al., 2009). Cannabis use of sufficient magnitude, or in individuals particularly vulnerable to the effects of cannabis, may lead to compromised brain functioning, causing a breakdown of reality testing. In addition, adolescent cannabis use seems to cause an especially strong risk for later psychosis (Caspi et al., 2005; Konings et al., 2008), consistent with a sensitive adolescent brain in the middle of important neurodevelopmental processes. Thus, cannabis would induce more transient cognitive changes that mimic the typical cognitive vulnerability. These changes can cause psychosis for some individuals, but will normally not cause the characteristic persistent cognitive impairments seen in schizophrenia. Consistent with this, fewer neurological soft signs have been shown in schizophrenia patients who also use cannabis (Bersani et al., 2002; Ruiz-Veguilla et al., 2009). Stirling et al. (2005) also reported fewer neurological soft signs, and better cognitive functioning, in the drug group after 10-12 years, and suggested that the drug group followed a different path to schizophrenia with less negative events of early brain development.

Further support for the imitation of cognitive vulnerability hypothesis is findings regarding age of onset of the disorder. The development of schizophrenia is usually seen in late adolescence/early adulthood. This is in line with a neurodevelopmental model (Weinberger, 1995), since the age of onset coincides with the late maturation of the prefrontal cortex through pruning of exuberant synapses and myelination of axons (Woo and Crowell, 2005). Studies have reported earlier age of onset in schizophrenia patients who have used cannabis (Stirling et al., 2005; Barnes et al., 2006). Consistent with this, data from our own laboratory showed four years earlier debut of schizophrenia in cannabis users (Løberg et al., 2003). Again, this suggests a different pathway to schizophrenia, and is consistent with a hypothesis stating that cannabis is an environmental factor imitating the effect of the typical cognitive vulnerability (Solowij and Michie, 2007).

\section{CONCLUDING REMARKS}

Cannabis seems to be a risk factor for the development of schizophrenia, mimicking the typical cognitive vulnerability. As an environmental factor, cannabis use has the potential for being influenced by interventions, thus indirectly having an effect on the development of schizophrenia. Accordingly, clinical implications (Moore et al., 2007) and public health implications (Arseneault et al., 2004a) have been suggested. A promising clinical intervention would be to monitor cannabis use in patients known to be vulnerable for psychosis, and help them to stay away from cannabis. Cannabis does not appear to create additive cognitive impairments, however, and cannabis-using patients may actually have better cognitive functioning. This could suggest that cannabis-related schizophrenia represents a different subtype, although few consistent clinical differences in regard to symptom profiles have been found (Boydell et al., 2007). This necessitates a better understanding of the paradox of better cognitive functioning, similar clinical profiles, and worse prognosis in this group, through for instance 
longitudinal studies on the effect of previous and ongoing cannabis use on the fluctuations of cognitive and clinical functioning in schizophrenia.

Possibly cannabis mimics the typical cognitive vulnerability seen in schizophrenia. Solowij and Michie (2007) suggested that cannabis leads to similar cognitive impairment as what is typically seen in schizophrenia, but of a lower magnitude. Several studies have shown cognitive impairment during THC-intoxication (D'Souza et al., 2005; Morrison et al., 2009). The preliminary data from our own laboratory suggest more transient cognitive impairments in the cannabis group (Løberg et al., 2008). Perhaps cannabis causes a transient cognitive breakdown enabling the development of psychosis, in spite of the absence of proper cognitive vulnerability. Thus, the effects of cannabis on cognition and brain functioning model the cognitive vulnerability in schizophrenia, and understanding this cognitive breakdown may provide a unique window to understanding schizophrenia neurodevelopment.

\section{ACKNOWLEDGMENTS}

Financial support for the research reported in this article was given by Research Council of Norway (RCN), Haukeland University Hospital Strategic Research Programme, and Health Authority for Western Norway.

\section{REFERENCES}

Addington, J., and Addington, D. (1997). Substance abuse and cognitive functioning in schizophrenia. J. Psychiatry Neurosci. 22, 99-104.

Andreasson, S., Allebeck, P., Engstrom, A., and Rydberg, U. (1987). Cannabis and schizophrenia. A longitudinal study of Swedish conscripts. Lancet 2, 1483-1486.

Arseneault, L., Cannon, M., Poulton, R., Murray, R., Caspi, A., and Moffitt, T. E. (2002). Cannabis use in adolescence and risk for adult psychosis: longitudinal prospective study. BMJ 325 , 1212-1213.

Arseneault, L., Cannon, M., Witton, J., and Murray, R. (2004a). Cannabis as a potential causal factor in schizophrenia. In Marijuana and Madness, D. Castle and R. Murray, eds (Cambridge, Cambridge University Press), pp. 101-118.

Arseneault, L., Cannon, M., Witton, J., and Murray, R. M. (2004b). Causal association between cannabis and psychosis: examination of the evidence. $\mathrm{Br}$. J. Psychiatry 184, 110-117.

Barnes, T. R., Mutsatsa, S. H., Hutton, S. B., Watt, H.C., and Joyce, E. M. (2006). Comorbid substance use and age at onset of schizophrenia. Br. J. Psychiatry 188, 237-242.

Bersani, G., Orlandi, V., Gherardelli, S., and Pancheri, P. (2002). Cannabis and neurological soft signs in schizophrenia: absence of relationship and influence on psychopathology. Psychopathology 35, 289-295.

Boydell,J.,Dean, K., Dutta, R., Giouroukou, E., Fearon, P., and Murray, R. (2007). A comparison of symptoms and family history in schizophrenia with and without prior cannabis use: implications for the concept of cannabis psychosis. Schizophr. Res. 93, 203-210.

Carey, K. B., Carey, M. P., and Simons, J. S. (2003). Correlates of substance use disorder among psychiatric outpatients: focus on cognition, social role functioning, and psychiatric status. J. Nerv. Ment. Dis. 191, 300-308.

Caspari, D. (1999). Cannabis and schizophrenia: results of a follow-up study. Eur. Arch. Psychiatry Clin. Neurosci. 249, 45-49.

Caspi, A., Moffitt, T. E., Cannon, M., McClay, J., Murray, R., Harrington, H., Taylor, A., Arseneault, L., Williams, B. Braithwaite, A., Poulton, R., and Craig, I. W. (2005). Moderation of the effect of adolescent-onset cannabis use on adult psychosis by a functional polymorphism in the catechol-Omethyltransferase gene: longitudinal evidence of a gene $\mathrm{X}$ environment interaction. Biol. Psychiatry 57, 1117-1127.

Chambers, R. A., Krystal, J. H., and Self, D. W. (2001). A neurobiological basis for substance abuse comorbidity in schizophrenia. Biol. Psychiatry 50, $71-83$

Cleghorn, J. M., Kaplan, R. D., Szechtman, B., Szechtman, H., Brown, G. M., and Franco, S. (1991). Substance abuse and schizophrenia: effect on symptoms but not on neurocognitive function. J. Clin. Psychiatry 52, 26-30.

Corcoran, C. M., Kimhy, D., Stanford, A., Khan, S., Walsh, J., Thompson, J., Schobel, S., Harkavy-Friedman, J., Goetz, R., Colibazzi, T., Cressman, V., and Malaspina, D. (2008). Temporal association of cannabis use with symptoms in individuals at clinical high risk for psychosis. Schizophr. Res. 106, 286-293.

Coulston, C. M., Perdices, M., and Tennant, C. C. (2007a). The neuropsychological correlates of cannabis use in schizophrenia: lifetime abuse/dependence, frequency of use, and recency of use. Schizophr. Res. 96, 169-184.

Coulston, C. M., Perdices, M., and Tennant, C. C. (2007b). The neuropsychological of cannabis and other substance use in schizophrenia: review of the literature and critical evaluation of methodological issues. Aust. N Z J. Psychiatry, 41, 869-884.

Dean, B., Sundram, S., Bradbury, R. Scarr, E., and Copolov, D. (2001). Studies on $[3 \mathrm{H}] \mathrm{CP}-55940$ binding in the human central nervous system: regional specific changes in density of cannabinoid-1 receptors associated with schizophrenia and cannabis use. Neuroscience 103, 9-15.

Degenhardt, L., Tennant, C., Gilmour, S., Schofield, D., Nash, L., Hall, W. and McKay, D. (2007). The temporal dynamics of relationships between cannabis, psychosis and depression among young adults with psychotic disorders: findings from a 10-month prospective study. Psychol. Med. 37, 927-934.

Di Forti, M., Morrison, P. D., Butt, A., and Murray, R. M. (2007). Cannabis use and psychiatric and cogitive disorders: the chicken or the egg? Curr. Opin. Psychiatry 20, 228-234.

Drake, R. E., Osher, F. C., Noordsy, D. L., Hurlbut, S. C., Teague, G. B., and Beaudett, M. S. (1990). Diagnosis of alcohol use disorders in schizophrenia. Schizophr. Bull. 16, 57-67.

D’Souza, D. C., Abi-Saab, W. M. Madonick, S., Forselius-Bielen, K. Doersch, A., Braley, G., Gueorguieva, R., Cooper, T. B., and Krystal, J. H (2005).Delta-9-tetrahydrocannabinol effects in schizophrenia: implications for cognition, psychosis, and addiction. Biol. Psychiatry 57, 594-608.

D’Souza, D. C., Cho, H.-S., Perry, E. B., and Krystal, J.H. (2004). Cannabinoid "model" psychosis, dopamine-cannabinoid interactions and implications for schizophrenia. In Marijuana and Madness, D. Castle and R. Murray, eds (Cambridge, Cambridge University Press), pp. 142-165.

Ferdinand, R. F., Sondeijker, F., van der Ende, J., Selten, J. P., Huizink, A., and Verhulst, F. C. (2005). Cannabis use predicts future psychotic symptoms, and vice versa. Addiction 100 612-618.

Fergusson, D. M., Horwood, L. J., and Swain-Campbell,N.R.(2003). Cannabis dependence and psychotic symptoms in young people. Psychol. Med. 33, 15-21.

Fusar-Poli, P., Crippa, J.A., Bhattacharyya, S., Borgwardt, S. J., Allen, P., MartinSantos, R., Seal, M., Surguladze, S. A., O'Carrol, C., Atakan, Z., Zuardi, A. W., and McGuire, P. K. (2009). Distinct effects of \{delta\}9-tetrahydrocannabinol and cannabidiol on neural activation during emotional processing. Arch. Gen. Psychiatry 66, 95-105.

Grech, A., Van Os, J., Jones, P. B., Lewis, S. W., and Murray, R. M. (2005) Cannabis use and outcome of recent onset psychosis. Eur. Psychiatry 20, 349-353.

Green, M. F. (1996). What are the functional consequences of neurocognitive deficits in schizophrenia? Am. J. Psychiatry 153, 321-330.

Gschwandtner, U., Aston, J., Borgwardt, S., Drewe, M., Feinendegen, C. Lacher, D., Lanzarone, A., Stieglitz, R.-D., and Riecher-Rössler, A. (2003). Neuropsychological and neurophysiological findings in individuals suspected to be at risk for schizophrenia: preliminary results from the Basel early detection of psychosis study Fruherkennung von Psychosen (FEPSY). Acta Psychiatr. Scand. 108, 152-155.

Heaton, R. K., Gladsjo, J. A., Palmer, B. W., Kuck, J., Marcotte, T. D., and Jeste, D. V. (2001). Stability and course of neuropsychological deficits in schizophrenia. Arch. Gen. Psychiatry 58, 24-32.

Henquet, C., Krabbendam, L., Spauwen, J., Kaplan, C.,Lieb, R., Wittchen,H.U., and van Os, J. (2005a). Prospective cohort study of cannabis use, predisposition for psychosis, and psychotic symptoms in young people. BMJ 330, 11. 
Henquet, C., Murray, R., Linszen, D., and van Os, J. (2005b). The environment and schizophrenia: the role of cannabis use. Schizophr. Bull. 31, 608-612.

Henquet, C., Rosa,A., Delespaul, P., Papiol, S., Fananas, L., van Os, J., and MyinGermeys, I. (2009). COMT ValMet moderation of cannabis-induced psychosis: a momentary assessment study of 'switching on' hallucinations in the flow of daily life. Acta Psychiatr. Scand. 119, 156-160.

Henquet, C., Rosa, A., Krabbendam, L., Papiol, S., Fananas, L., Drukker, M., Ramaekers, J. G., and van Os, J. (2006). An experimental study of catechol-o-methyltransferase Val158Met moderation of delta9-tetrahydrocannabinol-induced effects on psychosis and cognition. Neuropsychopharmacology 31, 2748-2757.

Herman, M. (2004). Neurocognitive functioning and quality of life among dually diagnosed and nonsubstance abusing schizophrenia inpatients. Int. J. Ment. Health Nurs. 13, 282-291.

Jockers-Scherubl, M. C., Wolf, T., Radzei, N., Schlattmann, P., Rentzsch, J., Gomez-Carrillo de Castro, A., and Kuhl, K. P. (2007). Cannabis induces different cognitive changes in schizophrenic patients and in healthy controls. Prog. Neuropsychopharm. Biol. Psychiatry 31, 1054-1063.

Joyal, C. C., Halle, P., Lapierre, D., and Hodgins, S. (2003). Drug abuse and/ or dependence and better neuropsychological performance in patients with schizophrenia. Schizophr. Res. 63, 297-299.

Konings, M., Henquet, C., Maharajh, H. D., Hutchinson, G., and Van Os, J. (2008). Early exposure to cannabis and risk for psychosis in young adolescents in Trinidad. Acta Psychiatr. Scand. 118, 209-213.

Kristensen, K., and Cadenhead, K. S. (2007). Cannabis abuse and risk for psychosis in a prodromal sample. Psychiatry Res 151, 151-154.

Kumra, S., Thaden, E., DeThomas, C., and Kranzler, H. (2005). Correlates of substance abuse in adolescents with treatment-refractory schizophrenia and schizoaffective disorder. Schizophr. Res. 73, 369-371.

Larsen, T. K., Melle, I., Auestad, B., Friis, S., Haahr, U., Johannessen, J. O., Opjordsmoen, S., Rund, B. R., Simonsen, E., Vaglum, P., and McGlashan, T. H. (2006). Substance abuse in first-episode non-affective psychosis. Schizophr. Res. 88, 55-62.

Leweke, F. M., Giuffrida, A., Wurster U., Emrich, H. M., and Piomelli, D.
(1999). Elevated endogenous cannabinoids in schizophrenia. Neuroreport 10, 1665-1669.

Linszen, D. H., Dingemans, P. M., and Lenior, M. E. (1994). Cannabis abuse and the course of recent-onset schizophrenic disorders. Arch. Gen. Psychiatry 51, 273-279.

Liraud, F., and Verdoux, H. (2002) Effect of comorbid substance use on neuropsychological performance in subjects with psychotic or mood disorders. Encephale 28, 160-168.

Løberg, E. M., Hugdahl, K., and Jørgensen, H. A. (2008). Lower neurocognitive vulnerability in schizophrenia with a history of cannabis abuse? Abstract. Schizophr. Res., 98(Suppl. S), 73.

Løberg, E. M., Jørgensen, H. A., and Hugdahl, K. (2003). The effects of previous drug abuse on neurocognition in schizophrenia. Abstract. J. Int. Neuropsychol. Soc. 9, 172.

Macleod, J., Oakes, R., Copello, A., Crome, I., Egger, M., Hickman, M., Oppenkowski, T., Stokes-Lampard, H., and Davey Smith, G. (2004). Psychological and social sequelae of cannabis and other illicit drug use by young people: a systematic review of longitudinal, general population studies. Lancet 363, 1579-1588.

Mata, I., Rodriguez-Sanchez, J. M. Pelayo-Teran, J. M., Perez-Iglesias, R., Gonzalez-Blanch, C., Ramirez-Bonilla, M., Martinez-Garcia, O., VazquezBarquero, J.L., and Crespo-Facorro, B. (2008). Cannabis abuse is associated with decision-making impairment among first-episode patients with schizophrenia-spectrum psychosis. Psychol. Med. 38, 1257-1266.

McCleery, A., Addington, J., and Addington, D. (2006). Substance misuse and cognitive functioning in early psychosis: a 2 year follow-up. Schizophr. Res. 88, 187-191.

Moore, T. H., Zammit, S., LingfordHughes, A., Barnes, T. R., Jones, P. B., Burke, M., and Lewis, G. (2007). Cannabis use and risk of psychotic or affective mental health outcomes: a systematic review. Lancet 370 , 319-328.

Morrison, P. D., Zois, V., McKeown, D. A., Lee, T. D., Holt, D. W., Powell, J. F., Kapur, S., and Murray, R. M. (2009). The acute effects of synthetic intravenous $\Delta 9$-tetrahydrocannabinol on psychosis, mood and cognitive functioning. Psychol. Med. 39, 1607-1616.

Neuchterlein, K. H., Dawson, M. E., and Green, M. F. (1994). Informationprocessing abnormalities as neuropsychological vulnerability indicators for schizophrenia. Acta Psychiatr. Scand. 90, 71-79.
Palmer, B. W., Dawes, S. E., and Heaton, R. K. (2009). What do we know about neuropsychological aspects of schizophrenia? Neuropsychol Rev, 19 , 365-384.

Palmer, B. W., Heaton, R. K., Paulsen, J. S., Kuck, J., Braff, D., Harris, M. J. Zisook, S., and Jeste, D. V. (1997) Is it possible to be schizophrenic yet neuropsychologically normal? Neuropsychology 11, 437-446.

Pencer, A., and Addington, J. (2003) Substance use and cognition in early psychosis. J. Psychiatry Neurosci. 28, 48-54.

Potvin, S., Briand, C., Prouteau, A., Bouchard, R. H., Lipp, O., Lalonde, P., Nicole, L., Lesage, A., and Stip, E. (2005). CANTAB explicit memory is less impaired in addicted schizophrenia patients. Brain Cogn. 59, 38-42.

Potvin, S., Joyal, C. C., Pelletier, J., and Stip, E. (2008). Contradictory cognitive capacities among substanceabusing patients with schizophrenia: a meta-analysis. Schizophr. Res. 100 242-251.

Quickfall, J., and Crockford, D. (2006). Brain neuroimaging in cannabis use: a review. J. Neuropsychiatry Clin. Neurosci. 18, 318-332.

Rais, M., Cahn, W., Van Haren, N. Schnack, H., Caspers, E., Hulshoff Pol, H., and Kahn, R. (2008). Excessive brain volume loss over time in cannabis-using first-episode schizophrenia patients. Am. J. Psychiatry 165 490-496.

Regier, D. A., Farmer, M. E., Rae, D. S., Locke, B. Z., Keith, S. J., Judd L. L., and Goodwin, F. K. (1990). Comorbidity of mental disorders with alcohol and other drug abuse. Results from the Epidemiologic Catchment Area (ECA) Study. JAMA 264, 2511-2518.

Ringen, P. A., Melle, I., Birkenaes, A. B., Engh, J. A., Faerden, A., Vaskinn, A., Friis, S., Opjordsmoen, S., and Andreassen, O.A. (2008). The level of illicit drug use is related to symptoms and premorbid functioning in severe mental illness. Acta Psychiatr. Scand. 118, 297-304.

Ruiz-Veguilla, M., Gurpegui, M. Barrigon, M. L., Ferrin, M., Marin, E., Rubio, J. L., Gutierrez, B., Pintor A., and Cervilla, J. (2009). Fewer neurological soft signs among first episode psychosis patients with heavy cannabis use. Schizophr. Res. 107, 158-164.

Schnell, T., Koethe, D., Daumann, J., and Gouzoulis-Mayfrank, E. (2009) The role of cannabis in cognitive functioning of patients with schizophrenia. Psychopharmacology (Berl) 205, 45-52.
Semple, D. M., McIntosh, A. M., and Lawrie, S. M. (2005). Cannabis as a risk factor for psychosis: systematic review. J. Psychopharm. 19, 187-194.

Sevy, S., Burdick, K. E., Visweswaraiah, H., Abdelmessih, S., Lukin, M., Yechiam, E., and Bechara, A. (2007). Iowa gambling task in schizophrenia: a review and new data in patients with schizophrenia and co-occurring cannabis use disorders. Schizophr. Res. 92, 74-84.

Sevy, S., Robinson, D. G., Holloway, S., Alvir, J. M., Woerner, M. G., Bilder, R., Goldman, R., Lieberman, J., and Kane, J.(2001). Correlates of substance misuse in patients with first-episode schizophrenia and schizoaffective disorder. Acta Psychiatr. Scand. 104, 367-374.

Smit, F., Bolier, L., and Cuijpers, P. (2004). Cannabis use and the risk of later schizophrenia: a review. Addiction 99, 425-430.

Solowij, N., and Michie, P. T. (2007). Cannabis and cognitive dysfunction: parallels with endophenotypes of schizophrenia? J. Psychiatry Neurosci. $32,30-52$.

Stefanis, N. C., Delespaul, P., Henquet, C., Bakoula, C., Stefanis, C. N., and Van Os, J. (2004). Early adolescent cannabis exposure and positive and negative dimensions of psychosis. Addiction 99 1333-1341.

Stirling, J., Lewis, S., Hopkins, R., and White, C. (2005). Cannabis use prior to first onset psychosis predicts spared neurocognition at 10 year follow-up. Schizophr. Res. 75 , 135-137.

Thoma, P., and Daum, I. (2008). Working memory and multi-tasking in paranoid schizophrenia with and without comorbid substance use disorder. Addiction 103, 774-786.

Thoma, P., Wiebel, B., and Daum, I. (2007). Response inhibition and cognitive flexibility in schizophrenia with and without comorbid substance use disorder. Schizophr. Res. 92, 168-180.

Tien, A. Y., and Anthony, J. C. (1990) Epidemiological analysis of alcohol and drug use as risk factors for psychotic experiences. J. Nervous Mental Disease 178, 473-480.

van Os, J., Bak, M., Hanssen, M., Bijl, R. V., de Graaf, R., and Verdoux, H. (2002). Cannabis use and psychosis: a longitudinal population-based study. Am. J. Epidem. 156, 319-327.

Verdoux, H. (2004). Cannabis and psychosis proneness. In Marijuana and Madness, D. Castle and R. Murray, eds (Cambridge, Cambridge University Press), pp. 75-88. 
Weinberger, D. R. (1995). From neuropathology to neurodevelopment. Lancet 346, 552-557.

Wobrock, T., Sittinger, H., Behrendt, B., D'Amelio, R., and Falkai, P. (2009). Comorbid substance abuse and brain morphology in recent-onset psychosis. Eur. Arch. Psychiatry Clin. Neurosci. 259, 28-36.

Wobrock, T., Sittinger, H., Behrendt, B., D'Amelio, R., Falkai, P., and Caspari, D. (2007). Comorbid substance abuse and neurocognitive function in recent-onset schizophrenia. Eur. Arch. Psychiatry Clin. Neurosci. 257, 203-210.

Woo, T. U., and Crowell, A. L. (2005). Targeting synapses and myelin in the prevention of schizophrenia. Schizophr. Res. 73, 193-207.

Zammit, S., Allebeck, P., Andreasson, S., Lundberg, I., and Lewis, G. (2002). Self reported cannabis use as a risk factor for schizophrenia in Swedish conscripts of 1969: historical cohort study. BMJ 325, 1199.

Conflict of Interest Statement: The authors declare that the research was conducted in the absence of any commercial or financial relationships that could be construed as a potential conflict of interest.

Received: 01 June 2009; paper pending published:22 August 2009; accepted:04November 2009; published online: 24 November 2009.
Citation: Løberg EM and Hugdahl K (2009) Cannabis use and cognition in schizophrenia. Front. Hum. Neurosci. 3:53. doi 10.3389/neuro.09.053.2009

Copyright (c) 2009 Løberg and Hugdahl. This is an open-access article subject to an exclusive license agreement between the authors and the frontiers research foundation, which permits unrestricted use, distribution, and reproduction in any medium, provided the original authors and source are credited. 